\title{
A novel DOPO-g-KH550 modification wood fibers and its effects on the properties of composite phenolic foams
}

\author{
Yufeng $\mathrm{Ma}^{1^{*}}$, Xiang Geng ${ }^{1}$, Xi Zhang ${ }^{1}$, Chunpeng Wang ${ }^{2}$, Fuxiang $\mathrm{Chu}^{3}$ \\ ${ }^{1}$ Nanjing Forestry University, College of Materials Science and Engineering, Nanjing 210037; \\ ${ }^{2}$ Institute of Chemical Industry of Forestry Products, CAF, Jiangsu Province, Nanjing 210042, China \\ ${ }^{3}$ Chinese Academy of Forestry, Beijing 100091, China \\ "Corresponding author: e-mail: yufengma@163.com (YF.Ma)
}

\begin{abstract}
A novel 9, 10-dihydro-9-oxa-10-phosphaphenanthrene-10-oxide (DOPO) graft $\gamma$-amino propyl triethoxy silane (KH550) was synthesized and introduced on the surface of wood fiber. Finally DOPO-g-KH550 treated wood fiber (DKTWF) was used to prepare DKTWF composite phenolic foams (DKTWFCPF). The structures of DOPO-g- KH550 was acknowledged by Fourier transform infrared (FT-IR) and nuclear magnetic resonance ( $\left.{ }^{1} \mathrm{H}-\mathrm{NMR}\right)$. The structures of DKTWF were confirmed by FT-IR. Compared with wood fiber, the diffraction peaks' position was basically unchanged, but the crystallinity was slightly increased and thermal stability were dramatically improved, $\mathrm{T}_{5 \%}$ and $\mathrm{T}_{\max }$ increased by $21.9^{\circ}$ and $36.1^{\circ}$ respectively. But the char yield $\left(800^{\circ}\right)$ was slightly reduced. With the dosage of DKWF, there were different degrees of improvement including the mechanical properties, flame retardancy and microstructure of DKTWFCPF. Comprehensive analysis, the interfacial compatibility was significantly improved between DKTWF and phenolic resin, and the suitable content of DKTWF was 4\%.
\end{abstract}

Keywords: DOPO, Wood Fiber, $\Gamma$-amino propyl triethoxy silane; Composites, Characterization.

\section{INTRODUCTION}

Phenolic foam (PF) is one of excellent retardant material, which is characterized with low thermal conductivity and low toxic gas during fire, and has been widely applied in the thermal insulation fields: architecture, factory pipeline and transportation ${ }^{1,2}$. However, the high brittleness is one of greatest defect of phenolic foam, and greatly limits its large-scale application ${ }^{3,4}$. As a natural environmentally friendly material, wood fiber has excellent properties: low density, high tensile and flexural moduli ${ }^{5-9}$, which is widely applied in the field of polymer composite materials ${ }^{10-12}$. However its inherent hydrophilic and poor compatibility between wood fiber and polymers which results in poor adhesion. Silane coupling agents are commonly used to modify wood fibers to improve interfacial compatibility between wood fiber and polymer matrix ${ }^{13},{ }^{14}$. $\Gamma$-amino propyl triethoxy silane (KH550) is an excellent silane coupling agent, which contains alkoxy silane and amino group which can interact with hydrophilic group of wood fiber surface and hydrophobic polymers, and amino group also provides convenience for modification. Although the mechanical properties of treated wood fiber (using silane coupling agent) composite PFs are improved, and interfacial compatibility is also enhanced between treated wood fiber and polymers, limited oxygen index (LOI) of composite $\mathrm{PFs}$ are reduced compared with $\mathrm{PF}^{3,15}$. Therefore it is necessary to fire retardant treatment of wood fiber.

9,10-dihydro-9-oxa-10-phosphaphenanthrene-10-oxide(DOPO) is a halogen-free phosphorous flame retardant, which is characterized with smokeless, non-toxic, non-migration, durable flame retardant properties, and the multiple structural diversification by functionalization ${ }^{16-21}$. The molecular structure of DOPO contains six-membered phosphorus heterocyclic structure, and phosphorus atoms have active lone pair electrons, which are prone to nucleophilic addition reaction. The active hydrogen of P-H bond can be reacted with a variety of electron-deficient derivatives, leading to a wide range of compounds with phosphaphenanthrene skeleton ${ }^{22,23}$.

In this article, a novel DOPO-g-KH550 was synthesized. The structure of DOPO-g-KH550 was characterized by Fourier transform infrared spectroscope (FT-IR) and nuclear magnetic resonance $\left({ }^{1} \mathrm{H}\right.$ NMR) spectra. DOPO-g-KH550 was introduced on the surface of wood fiber (WF). FT-IR, X-ray diffraction (XRD), scanning electron microscope (SEM) and thermogravimetric analysis (TGA) of DOPO-g-KH550 treated wood fiber (DKTWF) were determined. Finally treated wood fibers were used to prepare DKMWF composite phenolic foams (DKTWFCPF). The mechanical properties, flame resistance, and microstructure of DKTWFCPF were measured.

\section{EXPERIMENTAL}

\section{Material}

9,10-dihydro-9-oxa-10-phosphaphenanthrene-10-oxide (DOPO) was buyed from Shenzhen Jinlong Chemical Technology Co., Ltd. $\Gamma$-amino propyltriethoxy silane (KH550) was obtained from United States Carbon Company; Wood fiber was obtained from Guangxi Fenglin Wood Industry Group Co., Ltd. Phenolic resin (PR) were obtained from Institute of Chemical Industry of Forestry Products, CAF. Polysorbate-80, petroleum ether, formic acid and dicumyl peroxide (DCP) were obtained from Sinopharm Group Chemical Reagent Co. Ltd.;

\section{Synthesis of DOPO-g-KH550}

DOPO $(0.13 \mathrm{~mol})$ and KH550(0.05 mol $)$ were added into a $250 \mathrm{~mL}$ four-necked round bottom flask fitted with stirrer, aerated nitrogen for 5 minutes, and heated to $140 \sim 150^{\circ} \mathrm{C}$ and reacted $5 \mathrm{~h}$ under anaerobic environment. Then cooled to $120^{\circ} \mathrm{C}$, added toluene $(60 \mathrm{~mL})$ and Vacuum suction filtration. Then cooled to $75^{\circ} \mathrm{C}$, added tetrahydrofuran $(50 \mathrm{~mL})$ and Vacuum suction filtration. 
Subsequently, DOPO-g-KH550 was dried to a constant weight in a vacuum drying oven at $50^{\circ} \mathrm{C}$ (Fig. 1).

\section{DOPO-g-KH550 treatment of wood fiber (DKTWF)}

Wood fibers were treated with silane solution (2 wt\% DOPO-g-KH550, $2 \mathrm{wt} \%$ DCP, and the $\mathrm{pH}$ adjusted to 3.5 with formic acid) for $4 \mathrm{~h}$. Finally, wood fibers were dried for $24 \mathrm{~h}$ at $60^{\circ} \mathrm{C}$.

\section{Preparation of wood fiber composite PFs}

Surfactants (Polysorbate-80), acid curing agents, blowing agents (petroleum ether), treated wood fibers were added into phenolic resin and mixed well, then poured into the mold. The PFs were obtained after foaming for $40 \mathrm{~min}$ at $70^{\circ} \mathrm{C}$.

\section{Measurements and characterization}

FT-IR Measurements. FT-IR spectra were recorded on a Nicolet IS10 FT-IR spectrometer with $\mathrm{KBr}$ pellets under air atmosphere.

${ }^{1} \mathrm{H}$ NMR Measurements. ${ }^{1} \mathrm{H}-\mathrm{NMR}$ was conducted on DRX 500 NMR spectrometer (400 MHz) (Bruker, Germany) at room temperature using tetramethylsilane (TMS) as an internal reference.

X-ray diffraction Measurements. X-ray diffraction of wood fibers was recorded with Shimadzu 6000X X-ray diffraction measurements.

Scanning electron microscopy (SEM) of wood fibers and foams. The micro morphology observation of wood fibers and phenolic foams was carried out using a Hitachi S3400-Nscanning electron microscope.

Thermogravimetric analysis (TGA). Thermogravimetric analysis (TGA) was conducted on a NETZCSH TG 209 F3 TGA system, ramping from 35 to $800^{\circ} \mathrm{C}$ with a rate of $10^{\circ} \mathrm{C} / \mathrm{min}$.

Mechanical Properties Measurements of foams. Compression strength measured by the standard ISO $844: 2014$. Bending strength measured by the standard ISO 1209-1:2012. Tensile properties measured by the standard ISO 1926-2009.

Limited oxygen index (LOI). LOI was measured using a JF-3 LOI instrument (LOI analysis instrument company, Jiangning County, China) according to ISO 4589-1-2017.

\section{RESULTS AND DISCUSSION}

\section{The structure of DOPO-g-KH550}

FT-IR. Figure 2 shows FT-IR spectra of DOPO-g-KH550. The FT-IR analysis of DOPO was shown as follows ${ }^{24-26}$ : $2436 \mathrm{~cm}^{-1}(\mathrm{P}-\mathrm{H}), 1593 \mathrm{~cm}^{-1}$ and 1605 $\mathrm{cm}^{-1}$ (phenyl group), $1477 \mathrm{~cm}^{-1}$ (P-phenyl), $1236 \mathrm{~cm}^{-1}$ $(\mathrm{P}=\mathrm{O}), 903 \mathrm{~cm}^{-1}$ (P-O-phenyl). The FT-IR analysis of KH55027, 28: $3368 \mathrm{~cm}^{-1}$ and $1580 \mathrm{~cm}^{-1}(\mathrm{~N}-\mathrm{H}), 1078$ $\mathrm{cm}^{-1}(\mathrm{Si}-\mathrm{O}), 2974 \mathrm{~cm}^{-1}\left(-\mathrm{CH}_{3}\right), 2927 \mathrm{~cm}^{-1}\left(-\mathrm{CH}_{2}-\right)$. In the structures of DOPO-g-KH550, The peaks (approximately $3358 \mathrm{~cm}^{-1}$ and $1581 \mathrm{~cm}^{-1}$ ) could be attributed to $\mathrm{N}-\mathrm{H}$. A peak at around $2436 \mathrm{~cm}^{-1}$ corresponded to $\mathrm{P}-\mathrm{H}$ which was disappeared. The peaks around $1595 \mathrm{~cm}^{-1}$ and 1606 $\mathrm{cm}^{-1}$ corresponded to phenyl group. The peak around $1238 \mathrm{~cm}^{-1}$ corresponded to $\mathrm{P}=\mathrm{O}$, and the peak around $906 \mathrm{~cm}^{-1}$ corresponded to P-O-phenyl. In addition, the capacious peak (about $1092 \mathrm{~cm}^{-1}$ ) could be attributed to $\mathrm{Si}-\mathrm{O}^{29}$. These indicated that DOPO-g-KH550 was successfully synthesized.

${ }^{\mathbf{1}} \mathbf{H}$ NMR. For further confirmation of molecular structure, ${ }^{1} \mathrm{H}$ NMR spectra of DOPO-g-KH550 are recorded and shown in Figure 3. In the structure of DOPO, around

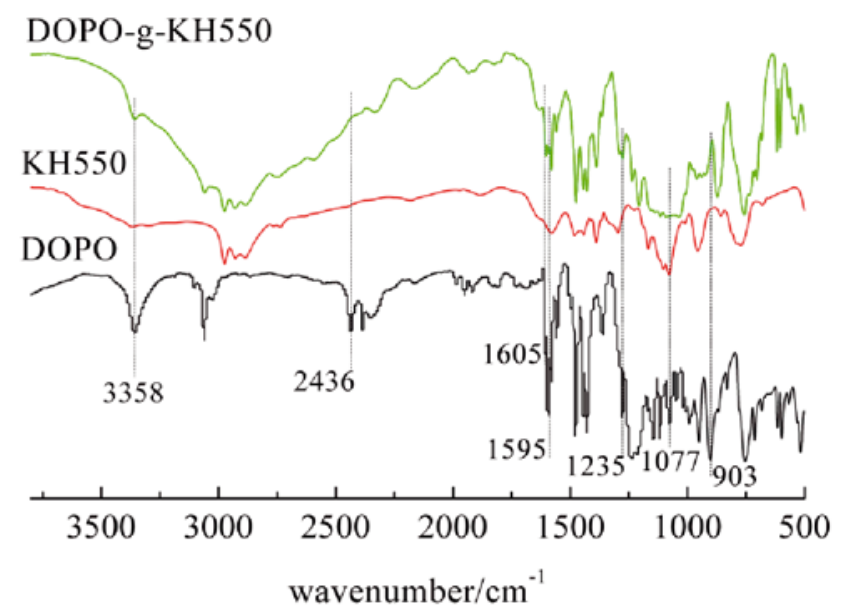

Figure 2. FT-IR spectra of DOPO-g-KH550

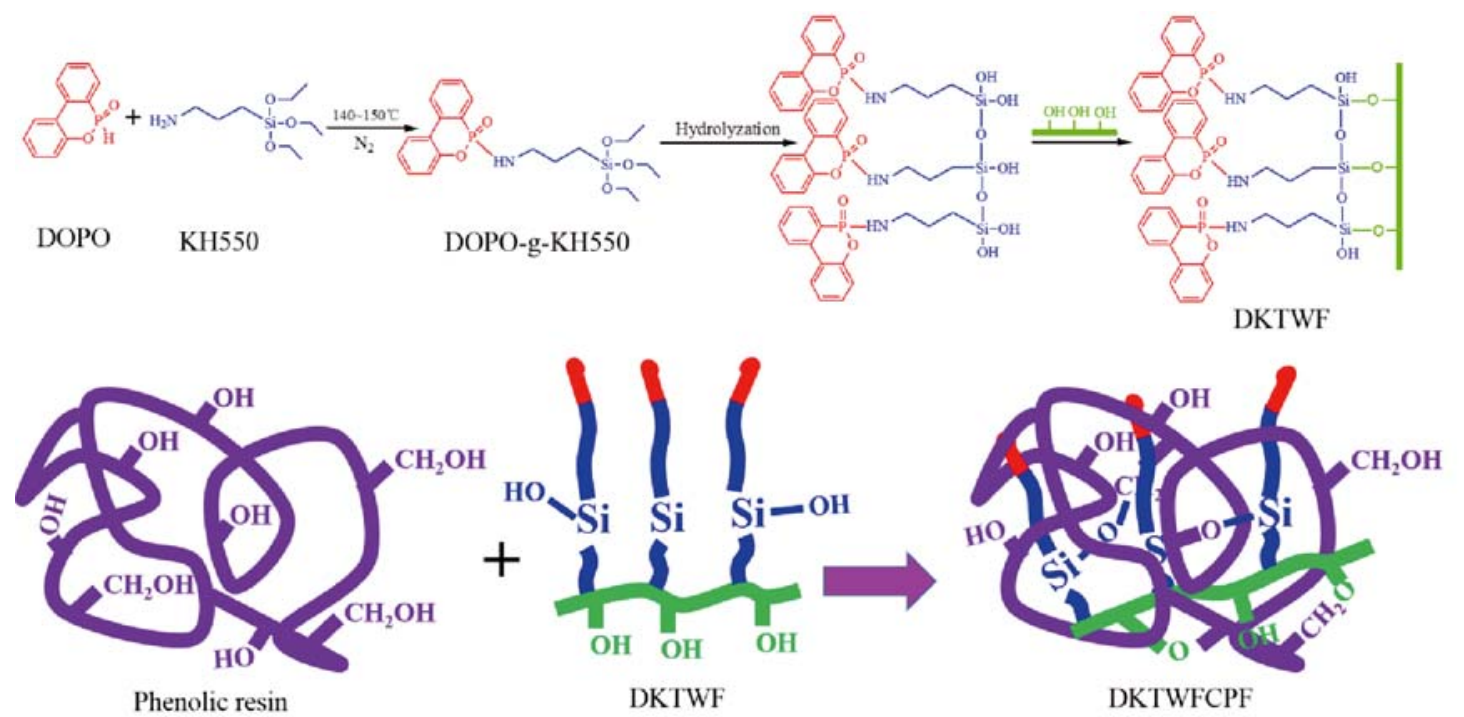

Figure 1. Scheme of DOPO-g- KH550 treated wood fibers composite PFs 


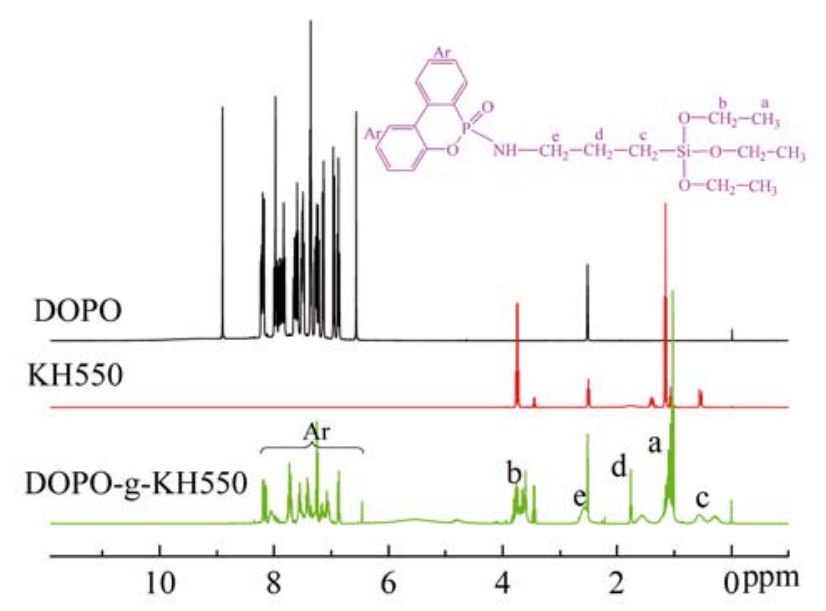

Figure 3. ${ }^{1} \mathrm{H}$ NMR spectra of DOPO-g-KH550

6.85-8.23 ppm corresponded to the phenyl protons. There were some new signals of the protons appears in the spectrum of DOPO-g-KH550. The signals of $\mathrm{H}^{\mathrm{a}}$, $\mathrm{H}^{\mathrm{b}}, \mathrm{H}^{\mathrm{c}}, \mathrm{H}^{\mathrm{d}}$ and $\mathrm{H}^{\mathrm{e}}$ were observed at $\delta$ 1.07-1.16 ppm, $\delta$ 3.45-3.79 ppm, $\delta$ 0.55-0.58 ppm, $\delta$ 2.50-2.65 ppm and $\delta$ $1.55-1.72 \mathrm{ppm}$. These protons were supported that the reaction were occurred between DOPO and KH550, and it was also confirmed that DOPO-g-KH550 was successfully synthesized again ${ }^{25,26,30,31}$.

\section{The properties of wood fibers}

FT-IR. FT-IR spectra of wood fibers are shown in Figure 4. It could be obviously found that the characteristic absorption bands of DKTWF was enhanced at $2900 \mathrm{~cm}^{-1}, 1425 \mathrm{~cm}^{-1}, 1050 \mathrm{~cm}^{-1}$, which were ascribed to $\mathrm{CH}_{2}, \mathrm{P}=\mathrm{O}$, and $\mathrm{Si}-\mathrm{O}$ respectively. The reason could be explained that the reaction was occurred between some of the hydroxyl groups on the surface of wood fiber and the hydroxyl groups of DOPO-g-KH550 (obtained after hydrolysis of silane), thus generated an ether bridge, and -Si-O-Si-, - Si-O-C- (around $1050 \mathrm{~cm}^{-1}$ ) and aliphatic chain $\left(\mathrm{CH}_{2}\right.$ in DOPO-g-KH550) were introduced in the surface of fiber ${ }^{25,32,33}$. These absorptions suggested that DOPO-g-KH550 was successfully introduced on the surface of wood fibers.

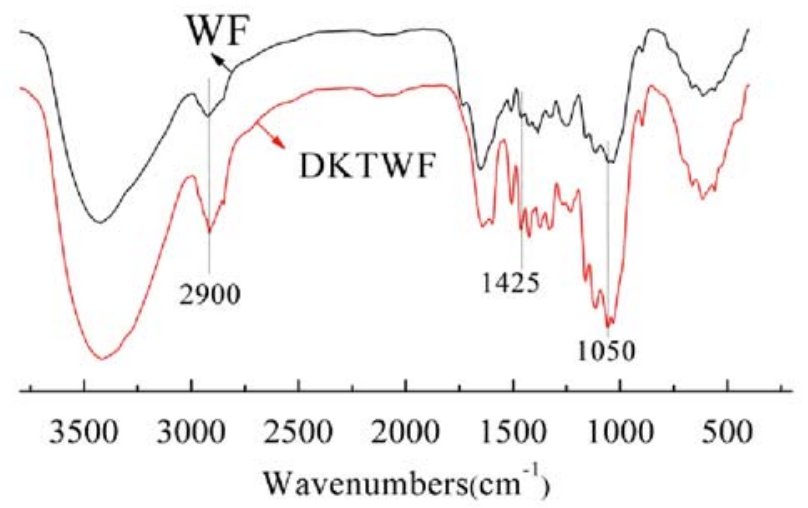

Figure 4. 4 FT-IR spectra of wood fibers

XRD. As shown in Figure 5. There were two diffraction peaks: $2 \theta=22.6^{\circ}$ and $15.6^{\circ 34}$. Compared with WF, the peaks' position of DKTWF was basically unchanged. This suggested that the crystal form of DKTWF did un- changed. But the peaks' intensity was slightly enhanced. The reason could be explained that during the process of modification, wood fibers were immersed in the acid solution, a partial of impurities, small and soluble molecules on the surface of wood fibers were dissolved and removed by suction filtration ${ }^{35}$. Hence the cellulose could be better arrangement, and the crystallinity of DKTWF was slightly enhanced.

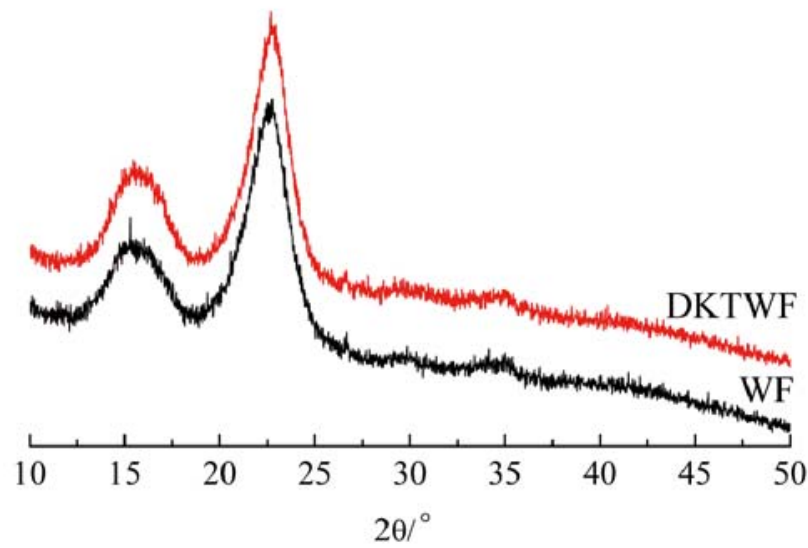

Figure 5. XRD spectra of wood fibers

SEM. As shown in Figure 6. The surface of WF was more rough than DKTWF, and was covered by pectin, waxy substance, impurities and so on $^{34}$. Compared with WF, the surface of DKTWF became smoother, and covered a thin layer of material. It could be interpreted that a partial of impurities, small and soluble molecules on the surface of wood fiber were dissolved and removed by suction filtration ${ }^{33}$. In the meantime, DOPO-g-KH550 was introduced on the surface of wood fibers. This was beneficial for improving interfacial compatibility between wood fibers and polymer matrix ${ }^{35}$.

Thermal Stability. As shown in Figure 7. It could be seen that $T_{5 \%}$ (evaluated by the temperature of $5 \mathrm{wt} \%$ mass loss) ${ }^{36,37}$ and $T$ max (the temperature of maximum weight loss rate) $)^{36,37}$ of DKTWF were increased from $244.7^{\circ} \mathrm{C}$ and $333.8^{\circ} \mathrm{C}$ for WF to $266.6^{\circ} \mathrm{C}$ and $369.9^{\circ} \mathrm{C}$. But the residue $\left(800^{\circ} \mathrm{C}\right)$ was slightly reduced from $30.37 \%$ to $28.75 \%$. These could be explained that the structure of DKTWF contained phosphorous and silicon, which could migrate to the external char layer and form a thick and compact the char layer, which could limit the emissions of volatile thermal degradation products and delay the process of degradation ${ }^{38-40}$. In addition, during the process of wood fibers modification, a partial of impurities, small and soluble molecules on the surface of wood fibers were dissolved and removed by suction filtration, which was one possible reason for the reduction in residual $\operatorname{carbon}\left(800^{\circ} \mathrm{C}\right)$.

\section{The properties of PFs}

Compression and bending strength. As shown in Figure 8. Compression strengths of DKTWF composite PF (DKTWFCPF) were less than that of PF. But compression strength gradually increased with the dosage of DKTWF. However bending strengths of DKTWFCPF were more than that of PF, and with the increase of DKTWF, firstly increased and then decreased. When amount of DKTWF was $4 \%$, bending strength was maximum. The 

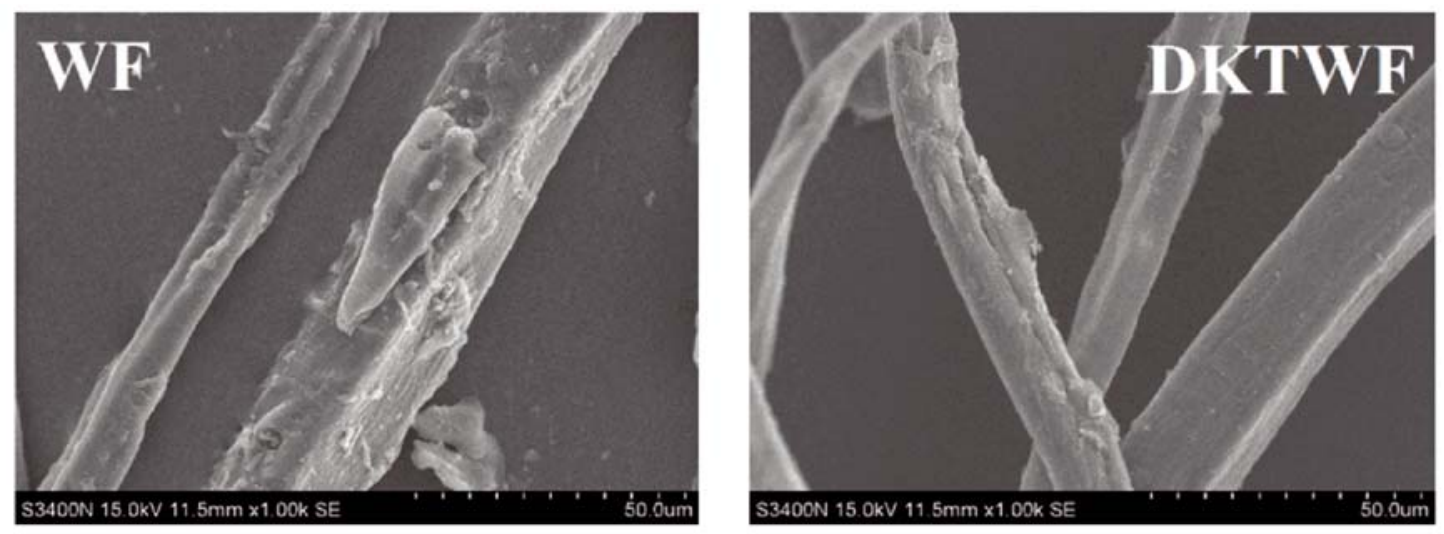

Figure 6. SEM micrographs $(1000 \times)$ of wood fibers
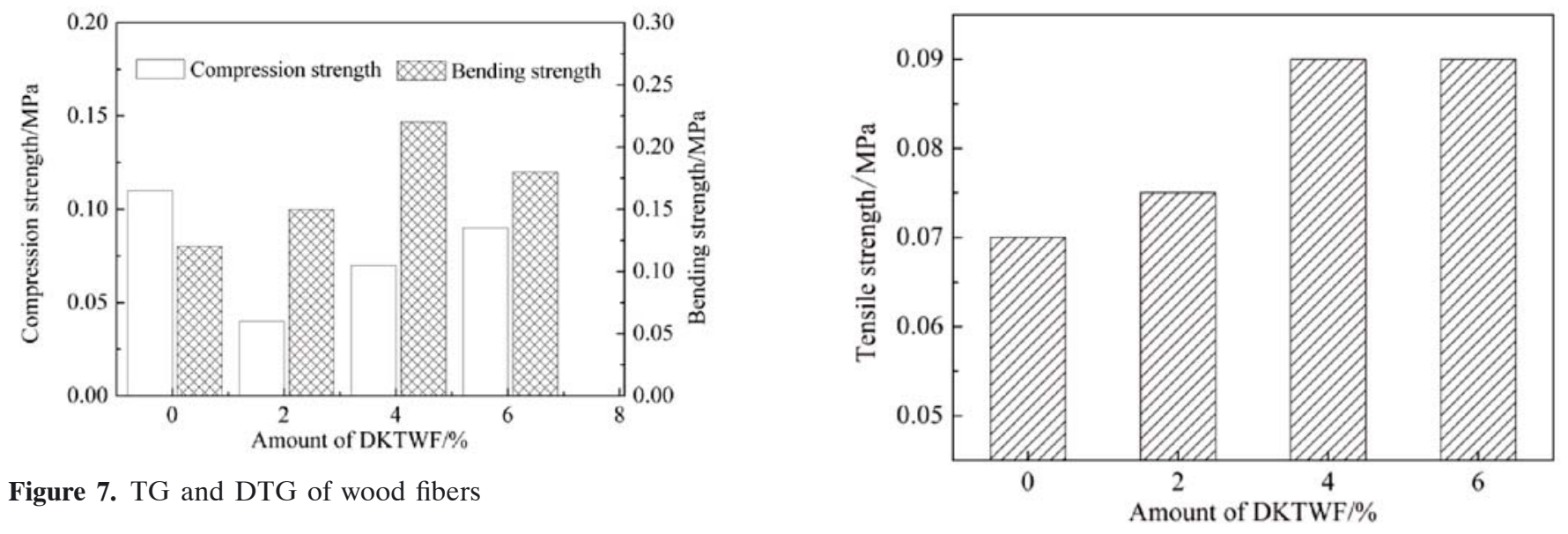

result showed that the toughness of composite foams was enhanced when DKTWF was introduced composite foam. And DKTWFCPF became softer than PF. Therefore compressive capacity of DKTWFCPF was less than PF. Due to the improvement of toughness, the resistance bending ability of DKTWFCPF was significantly better than PF, and when the resistance bending ability was maximum when amount of DKTWF was $4 \%$.

Tensile strength. Tensile strength is often used to evaluate the modification effect of interfacial compatibility between fibers and polymer matrix, the larger Tensile was strength of fiber composites, the more effect was for improving interfacial compatibility ${ }^{41-43}$. As shown in Figure 8. Compared with PF, tensile strengths of DKTWFCPF were dramatically improved. And with the dosage of DKTWF, tensile strength was gradually increased. When amount of DKTWF was more than 4\%, tensile strength was basically not increased. The result showed that the resistance tensile deformation ability of DKTWFCPF improved significantly. These indirectly confirmed that the interfacial compatibility was improved between DKTWF and phenolic resin. However the suitable dosage of DKTWF was about $4 \%$.

Limited oxygen index (LOI). LOI of PFs shows in Figure 10. With the dosage of DKTWF, LOIs of DKTWFCPF increased gradually. LOI of DKTWFCPF was identical to that of PF when amount of DKTWF was 4\%, and then LOI was more than PF's. However LOIs were more than $27 \%(34 \sim 35 \%)$, these foams were considered as flame resistant materials ${ }^{\mathbf{4 4}}$. The results showed that there was advantageous to improve flame retardancy of composite foams by DOPO-g-KH550 treated wood fibers. These could be interpreted that There contained phosphorus

Figure 8. Compression and bending strength of PFs

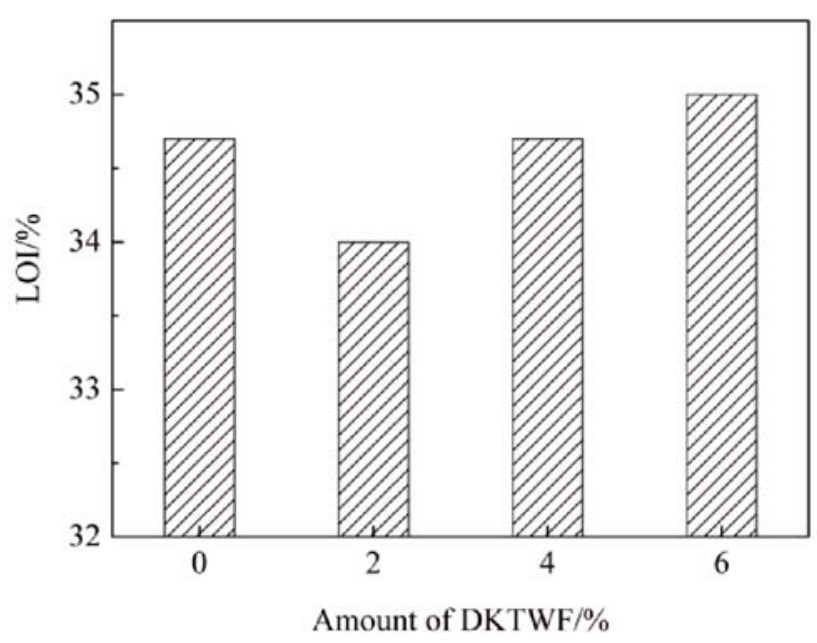

Figure 9. Tensile strength of PFs

and silicon element in structure of DOPO-g-KH550, the synergistic effect of phosphorus and silicon element improved the flame retardancy properties of DKTWFCPF slightly ${ }^{\mathbf{4 5}, 46}$. In addition, there was fewer flame retardants when the dosage of DKTWF was less (2\%), so LOI was less than that of PF. with the increase of DKTWF, there was more and more flame retardants, LOI was improved. Hence the suitable amount of DKTWF was equal to or more than $4 \%$.

SEM micrographs. As shown in Figure 11, when the dosage of DKWF was less than $6 \%$, the cell size of PFs was about at $200 \sim 400 \mu \mathrm{m}$, the cell distribution was more regular. There were some larger bubble cells $(500 \mu \mathrm{m})$ as 


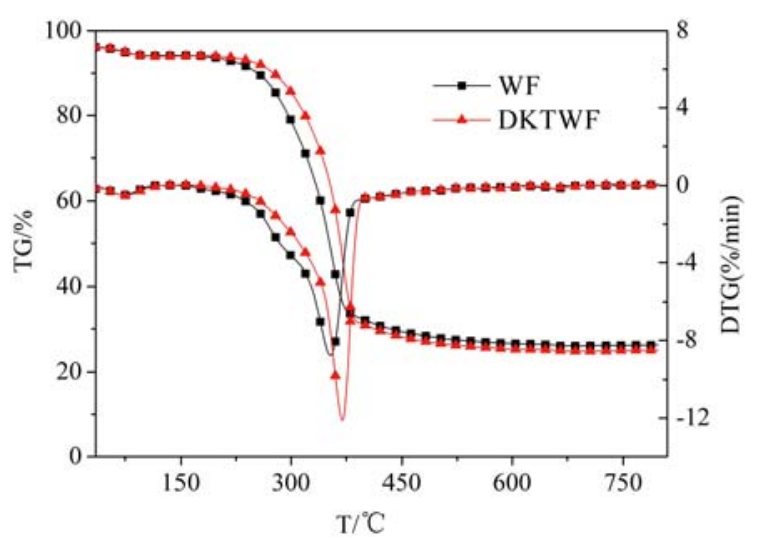

Figure 10. 10 LOI of PFs

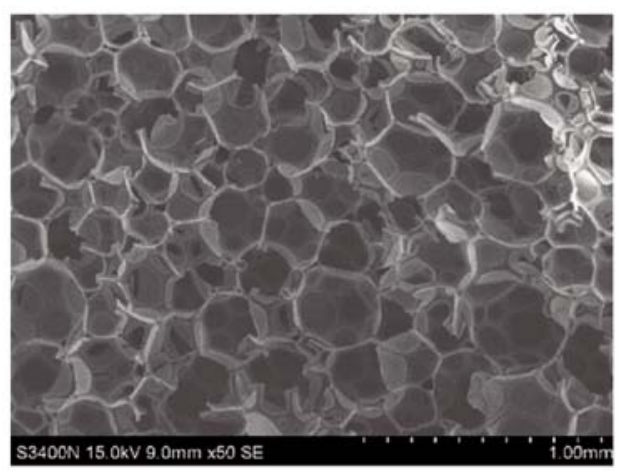

$0 \%$

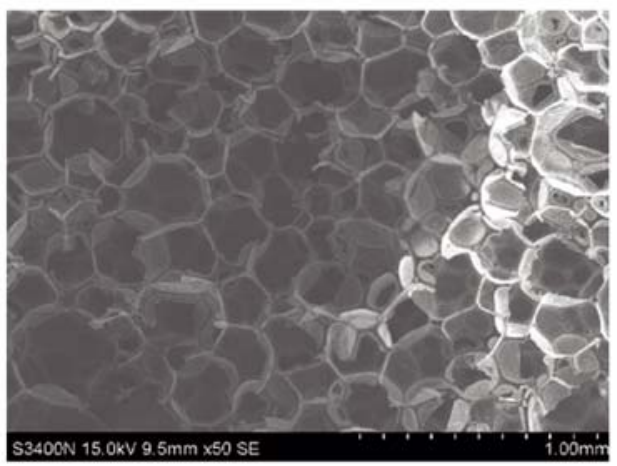

$4 \%$

Figure 11. SEM $(50 \times)$ of PFs

the amount of DKWF was $6 \%$. The results showed that the influence of DKWF on the properties of composite foams was less as the dosage was equal to or less than $4 \%$. It also confirmed that the interfacial compatibility was improved between DKWF and phenolic resin.

\section{CONCLUSIONS}

The structure of DOPO-g-KH550 was confirmed by FT-IR and ${ }^{1} \mathrm{H}$ NMR spectra, and was successfully introduced on the surface of wood fiber. Compared with WF, the diffraction peak positions of DKTWF were basically unchanged, but the crystallinity was slightly increased. And thermal stability was improved significantly. With the dosage of DKTWF, the mechanical properties, flame retardancy and microstructure of DKTWFCPF were increased. Comprehensive analysis, the interfa- cial compatibility was significantly improved between DKTWF and phenolic resin, and the suitable content of DKTWF was $4 \%$.

\section{ACKNOWLEDGES}

The work was partially financially supported by Youth Innovation Fund of Nanjing Forestry University (CX2016011); Nanjing Forestry University High-Level (High-Educated) Talents Scientific Research Funds (GXL2014033); The Priority Academic Program Development of Jiangsu Higher education institutions (PAPD).

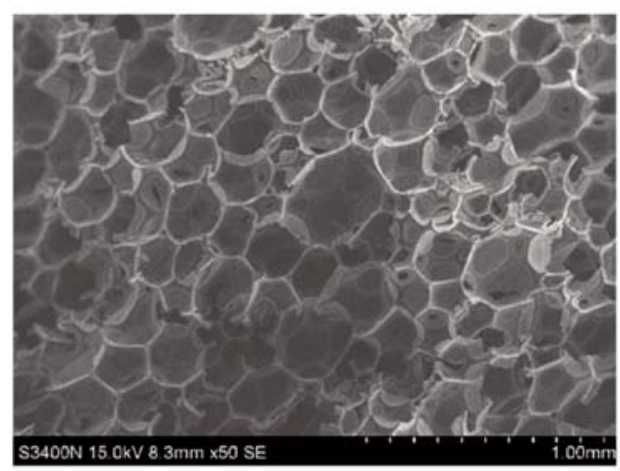

$2 \%$

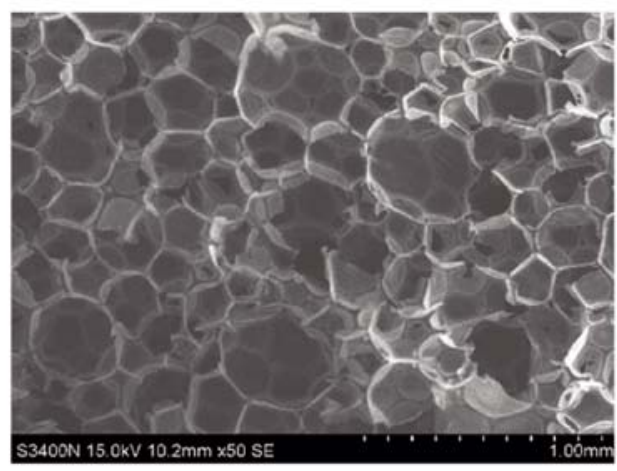

$6 \%$

\section{LITERATURE CITED}

1. Lei, S., Guo, Q., Zhang, D., Shi, J., Liu, L. \& Wei, X.. (2010). Preparation and properties of the phenolic foams with controllable nanometer pore structure. J. Appl. Poly. Sci. 117(6):3545-3550. DOI:10.1002/app.32280.

2. Yang, H., Wang, X., Yuan, H., Song, L., Hu, Y., Yuen, R.K.K. (2012). Fire performance and mechanical properties of phenolic foams modified by phosphorus-containing polyethers. J. Poly. Res. 19(3):9831. DOI:10.1007/s10965-012-9831-7

3. Ma, Y., Wang, C. \& Chum, F. (2017). Effects of fiber surface treatments on the properties of wood fiber-phenolic foam composites. Bioresources. 12(3), 4722-4736. DOI: 10.15376/ biores. 12.3.4722-4736.

4. Rangari, V.K., Hassan, T.A., Zhou, Y., Mahfuz, H., Jeelani, S. \& Prorok, B.C. (2010). Cloisite clay-infused phenolic foam nanocomposites. J. Appl. Polym. Sci. 103(1), 308-314. DOI:10.1002/app.25287. 
5. Bledzki, A.K. \& Gassan, J. (1999). Composites reinforced with cellulose based fibres. Prog. Polym. Sci. 24(2), 221-274. DOI: 10.1016/S0079-6700(98)00018-5.

6. Canché-Escamilla, G., Cauich-Cupul, J.I., Mendizábal, E., Puig, J.E., Vázquez-Torres, H. \& Herrera-Franco, P.J. (1999). Mechanical properties of acrylate-grafted henequen cellulose fibers and their application in composites. Composites Part A Applied Science \& Manufacturing. 30(3), 349-359. DOI: 10.1016/S1359-835X(98)00116-X.

7. Mitra, B.C., Basak, R.K. \& Sarkar, M. (1998). Studies on jute-reinforced composites, its limitations, and some solutions through chemical modifications of fibers. J. Appl. Polym. Sci. 67(6), 1093-1100. DOI:10.1002/(SICI)10974628(19980207)67:6< 1093:AID-APP17>3.0.CO;2-1.

8. Rana, A.K., Mandal, A., Mitra, B.C., Jacobson, R., Rowell, R. \& Banerjee, A.N.. (1998). Short jute fiber-reinforced polypropylene composites: Effect of compatibilizer. $J$. Appl. Polym. Sci. 69(2), 329-338. DOI: 10.1002/(SICI)10974628(19980711)69:2<329::AID-APP14> 3.0. CO;2-R.

9. Xie, Y., Hill, C.A.S., Xiao, Z., Militz, H. \& Mai, C. (2010). Silane coupling agents used for natural fiber/polymer composites: A review. Composites Part A. 41(7), 806-819. DOI: 10.1016/j. compositesa.2010.03.005.

10. Maldas, D. \& Kokta, B.V. (1993). Performance of Hybrid Reinforcements in PVC Composites: Part Iural fiber/polymer composites: A review. Compositesforcements. J. Testing \& Evaluation. 21(1), 5. DOI: 10.1177/073168449201101002.

11. Mohanty, A.K., Misra, M. \& Drzal, L.T. (2002). Sustainable Bio-Composites from Renewable Resources: Opportunities and Challenges in the Green Materials World. J. Polym. \& the Environ. 10(1-2), 19-26. DOI: 10.1023/A:1021013921916.

12. Sanadi, A.R., Caulfield, D.F., Rowell, R.M. (1994). Reinforcing polypropylene with natural fibers. Societyofplasticsengineers Inc. :v50(:n4):27-28. DOI: 10.1515/pjct-2017-0077.

13. Rider, A. \& Arnott, D. (2000). Boiling water and silane pre-treatment of aluminium alloys for durable adhesive bonding. International journal of adhesion and adhesives. 20(3), 209-220. DOI: 10.1016/S0143-7496(99)00046-9.

14. Mittal, K.L. (2007). Silanes and other coupling agents. CRC Press.

15. Ma, Y., Wang, C. \& Chu, F. (2017). The structure and properties of eucalyptus fiber/phenolic foam composites under $\mathrm{N}$-ng. International journal of adhesion and adhesives. Polymers \& the Environment. arch. mount of DKWF19(4), 116-121. DOI: $10.1515 /$ pjct-2017-0077.

16. Zhang, W., Li, X. \& Yang, R. (2011). Novel flame retardancy effects of DOPO-POSS on epoxy resins. Polymer Degradation \& Stability. 96(12), 2167-2173. DOI: 10.1016/ j.polymdegradstab.2011.09.016.

17. Zang, L., Wagner, S., Ciesielski, M. \& Mb, P. 2011.09.016.2011.09.016" f DOPO-PO-shaped and hyperbranched phosphorus-containing flame retardants in epoxy resins. Polymers for Advanced Technologies. 22(7), 1182ng flame retardan/pat.1990.

18. Perret, B., Schartela, M., Ciesielski, J. \& Diederichs, M. Dvanced Technologies. epoxy resins. Polymer Degradation \& Stability. $\gamma$-aminopropyl trimethoxy silane pretreatments. Polish Journal of Chemical Technology. was 6\%.47(5), 1081-1089. DOI: 10.1016/j.eurpolymj. 2011.02.008.

19. Dumitrascu, A. (2012). Flame retardant polymeric materials achieved by incorporation of styrene monomers containing both nitrogen and phosphorus. Polymer Degradation \& Stability. 97(12), 2611-2618. DOI: 10.1016/j.polymdegradstab.2012.07.012.

20. Sun, D. \& Yao, Y. (2011). Synthesis of three novel phosphorus-containing flame retardants and their application in epoxy resins. Polymer Degradation \& Stability. 96(10), 1720-1724. DOI: 10.1016/j.polymdegradstab.2011.08.004.

21. Wang, P. \& Cai, Z.. (2017). Highly efficient flame-retardant epoxy resin with a novel DOPO-based triazole compound:
Thermal stability, flame retardancy and mechanism. Polymer Degradation \& Stability. 137. DOI: 10.1016/j.polymdegradstab.2017.01.014.

22. Carja, I.D., D. Serbezeanu, T. Vladbubulac, C. Hamciuc, A. Coroaba, G. \& Lisa, C.G. L DOPO-based triazole compound: Thermal stability, flame retardancy and mechanism. Polymer Degradation \& Stability. ical Technlame retardant epoxy resins. J. Mater. Chem. A. 2(38), 16230-16241.DOI: 10.1039/c4ta03197k. 23. Yuxiang, O. \& Jianjun, L. (2006). Flame Retardants: Property, Preparation and Application. Beijing, Chemical Industry Press.

24. Shan, G., Jia, L., Zhao, T., Jin, C., Liu, R. \& Xiao, Y.. (2017). A novel DDPSi-FR flame retardant treatment and its effects on the properties of wool fabrics. Fibers \& Polymers. 18(11), 2196-2203. DOI: 10.1007/s12221-017-7244-2

25. Tang, C., Yan, H., Li, M. \& Lv, Q. (2017). A novel phosphorus-containing polysiloxane for fabricating high performance electronic material with excellent dielectric and thermal properties. J. Mater. Sci. Mater. Electron. 1-10. DOI: 10.1007/ s10854-017-7904-4

26. Fang, Y., Zhou, X., Xing, Z. \& Wu, Y. (2017). An effective flame retardant for poly(ethylene terephthalate) synthesized by phosphaphenanthrene and cyclotriphosphazene. J. Appl. Polym. Sci. 134(35). DOI: 10.1002/app.45246.

27. Wan, X., Zhan, Y., Long, Z., Zeng, G., He, Y. (2017). Core@double-shell structured magnetic halloysite nanotube nano-hybrid as efficient recyclable adsorbent for methylene blue removal. Chem. Eng. J. 330(15), 491-504.DOI: 10.1016/j. cej.2017.07.178.

28. Wan, X., Y. Zhan, Z. Long, G. Zeng, Y. Ren, Y. He. (2017). High-performance magnetic poly (arylene ether nitrile) nanocomposites: co-modification of $\mathrm{Fe}_{3} \mathrm{O}_{4}$ via mussel inspired poly (dopamine) and amino functionalized silane KH550. Applied Surface Science. 425(15), 905-914. DOI: 10.1016/j. apsusc.2017.07.136.

29. Su, J., J. Zhang. (2017). Effect of treated mica on rheological, cure, mechanical, and dielectric properties of ethylene propylene diene monomer (EPDM)/barium titanate (BaTiO3)/ mica. J. Appl. Polym. Sci. 134(19). DOI: 10.1002/app.44833.

30. Ni, P., Y. Fang, L. Qian, Y. Qiu. (2017). Flame-retardant behavior of a phosphorus/silicon compound on polycarbonate. J. Appl. Polym. Sci. DOI: 10.1002/app.45815.

31. Chen, T., Chen, X., Wang, M., Hou, P., Jie, C., Li, J., Xu, Y., Zeng, B. \& Dai, L. (2017). A novel halogen-free co-curing agent with linear multi-aromatic rigid structure as flame-retardant modifier in epoxy resin. Polymers for Advanced Technologies. DOI: 10.1002/pat.4170.

32. Cui, Y., Lee, S., Noruziaan, B., Cheung, M. \& Tao, J. (2008). Fabrication and interfacial modification of wood/recycled plastic composite materials. Composites Part A Applied Science \& Manufacturing. 39(4), 655-661. DOI: 10.1016/j. compositesa.2007.10.017.

33. Valadez-Gonzalez, A., Cervantes-Uc, J.M., Olayo, R. \& Herrera-Franco, P.J. (1999). Chemical modification of henequén fibers with an organosilane coupling agent. Composites Part B Engineering. 30(3), 321-331. DOI: 10.1016/S13598368(98)00055-9.

34. Wang, L., Han, G. \& Zhang, Y. (2007). Comparative study of composition, structure and properties of Apocynum venetum fibers under different pretreatments. Carbohydrate Polymers. 69(2), 391-397. DOI: 10.1016/j.carbpol.2006.12.028.

35. Lu, B., L. Zhang, J. Zeng, e. et al. (2005). Natural Fiber Composites Material Chemical Industry Press.

36. Huo, S., Wang, J., Yang, S., Chen, X., Zhang, B., Wu, Q. \& Zhang, B. (2017). Flame-retardant performance and mechanism of epoxy thermosets modified with a novel reactive flame retardant containing phosphorus, nitrogen, and sulfur. Polym. Adv. Technol. 29(1), 497-506. DOI: 10.1002/pat.4145.

37. Qiu, Y., Wachtendorf, V., Klack, P., Qian, L., Liu, Z. \& Schartel, B. (2017). Improved flame retardancy by synergy 
between cyclotetrasiloxane and phosphaphenanthrene/triazine compounds in epoxy thermoset. Polymer International. 66(12), 1883-1890. DOI: 10.1002/pi.5466.

38. Jia, P., Zhang, M., Hu, L., Liu, C., Feng, G., Yang, X., Bo, C. \& Zhou, Y. (2015). Development of vegetable oil based plasticizer for preparing flame retardant poly (vinyl chloride) materials. Rsc Advances. 5(93), 76392-76400. DOI: 10.1039/ c5ra10509a.

39. Jia, P., Zhang, M., Hu, L., Zhou, J., Feng, G. \& Zhou, Y. (2015). Thermal degradation behavior and flame retardant mechanism of poly(vinyl chloride) plasticized with a soybean-oil-based plasticizer containing phosphaphenanthrene groups. Polymer Degradation \& Stability. 121, 292-302. DIO: 10.1016/j. polymdegradstab.2015.09.020.

40. Jia, P., Zhang, M., Liu, C., Hu, L., Feng, G., Bo, C. \& Zhou, Y. (2015). Effect of chlorinated phosphate ester based on castor oil on thermal degradation of poly (vinyl chloride) blends and its flame retardant mechanism as secondary plasticizer. Rsc Advances. 5(51), 1169-41178. DOI: 10.1039/c5ra05784a.

41. Li, Y.Y., Wang, B. \& Ma, M.G. (2017). The enhancement performances of cotton stalk fiber/PVC composites by sequential two steps modification. J. Appl. Polym. Sci. 135(14):46090. DOI: $10.1002 /$ app. 46090

42. Tengsuthiwat, J., Asawapirom, U., Siengchin, S. \& Karger \& Kocsis, J. oacute, zsef. (2017). Mechanical, thermal, and water absorption properties of melamine\&ndash;formaldehyde-treated sisal fiber containing polylactic acid composites. J. Appl. Polym. Sci. 135(2), 45681. DOI: 10.1002/app.45681.

43. Ye, X., Wang, H., Wu, Z., Zhou, H. \& Tian, X. (2018). Synthesis and functional features of wood fiber-polypropylene materials: Based on wood fibers with assembling nano-coating via adopting simple in situ-hydrothermal mechanism. Polym. Composites. 39(1), 5-13. DOI: 10.1002/pc.23894.

44. Wang, C. \& Xu, G. (2010). Research on Hard-segment Flame-retardant Modification of Waterborne Polyurethane. China Coatings. DOI: 10.13531/j.cnki.china.coatings.2010.08.010.

45. Dong, Q., Liu, M., Ding, Y., Wang, F., Gao, C., Liu, P., Wen, B., Zhang, S. \& Yang, M. (2013). Synergistic effect of DOPO immobilized silica nanoparticles in the intumescent flame retarded polypropylene composites. Polym. Adv. Technol. 24(8), 732-739. DOI: $10.1002 /$ pat.3137.

46. Oktay, B., Emrah, Y., Ding, F., Wang, C., Gao, P., Liu, B., Wen, S., Zhang, M., Yang. (2013). Synergistic effect of DOPO immobilized silica nanoparticles in the intumescent flame retarded polyprop131(22), 132-142. DOI: 10.1016/j. polymer.2017.10.043. 